\title{
VARIABILIDADE GENÉTICA DE ACESSOS OBTIDOS DE POPULAÇÕES CULTIVADAS E SILVESTRES DE MARACUJAZEIRO-DOCE COM BASE EM MARCADORES RAPD ${ }^{1}$
}

\author{
GRACIELE BELLON ${ }^{2}$, FÁBIO GELAPEFALEIRO $^{3}$,JOSÉ RICARDOPEIXOTO ${ }^{4}$, \\ KEIZE PEREIRAJUNQUEIRA ${ }^{5}$, NILTON TADEU VILELAJUNQUEIRA ${ }^{3}$, \\ KENIA GRACIELLEDA FONSCECA ${ }^{2}$, MARCELOFIDELES BRAGA ${ }^{3}$
}

RESUMO- O maracujazeiro-doce (Passiflora alata Curtis), devido a preços diferenciados, vem ganhando importância dentro do mercado de frutas in natura. O melhoramento genético é fundamental para elevar a qualidade e a produtividade da cultura. Os marcadores moleculares do DNA têm sido muito úteis por permitirem a obtenção de um número praticamente ilimitado de polimorfismo genético sem influência do ambiente. Objetivou-se, neste trabalho, estudar a variabilidade genética de 17 acessos de maracujá-doce, com base em marcadores moleculares RAPD. Um acesso de P. quadrangularis e um de P. edulis foram utilizados como outgroups. Amostras de DNA genômico de cada acesso foram extraídas e 11 iniciadores decâmeros (OPD 04; 07; 08 e16; OPE 18 e 20; OPF 01 e 14; OPG 08; OPH 12 e 16) foram utilizados para a obtenção dos marcadores. Os marcadores obtidos foram convertidos em uma matriz de dados binários, a partir da qual foram estimadas as distâncias genéticas entre os acessos e realizadas análises de agrupamento e de dispersão gráfica. Do total de marcadores, considerando-se apenas os acessos de P. alata, observaramse $87(62,12 \%)$ bandas polimórficas, evidenciando a grande variabilidade intraespecífica. A análise de agrupamento realizada com base nas distâncias genéticas permitiu subdividir os 17 acessos de P. alata em, pelo menos, cinco grupos de similaridade genética. Os acessos silvestres foram os que mais contribuíram para a ampliação da base genética dos materiais estudados, abrindo perspectivas para o uso desses materiais em programas de melhoramento.

Termos para indexação: Passiflora alata Curtis., biotecnologia, melhoramento genético.

\section{GENETIC DIVERSITY OBTAINED FROM CULTIVATED POPULATION AND NATIVE ACCESSES OF SEEWT PASSION FRUIT BASED ON RAPD MARKERS}

\begin{abstract}
Sweet passion fruit (Passiflora alata Curtis) is gaining importance in the in natura fruit market due to differential value. Genetic breeding is crucial to improve crop quality and productivity. Molecular markers of DNA have been very useful by allowing obtaining a virtually unlimited number of genetic polymorphism without environment influence. This work's objective was to study the genetic variability of 17 sweet passion fruit accesses, using RAPD molecular markers. One access of $P$. quadrangularis and another of $P$. edulis were used as outgroups. Genomic DNA samples of each one of them were extracted and 11 decamers primers (OPD 04, 07, 08 e16; OPE 18 and 20; OPF 01 and 14; OPG 08; OPH 12 and 16) were used to obtain the markers. The markers have been converted into a matrix of binary data, used as base to estimate genetic distances between accesses and to perform grouping and graphic dispersion analysis. From the total amount of markers, considering only $P$. alata accesses, it was observed 87 (62.12\%) polymorphic bands, showing great intraspecific variability. Grouping analysis based on genetic distances allowed to subdivide $17 P$. alata accesses in, at least, five groups of genetic similarity. The wild accesses contributed the most to the genetic basis expansion of the studied materials, opening good prospects for their use in breeding programs.
\end{abstract}

Index Terms: Passiflora alata Curtis, biotechnology, genetic breeding.

${ }^{1}$ (Trabalho 095-08). Recebido em: 11-04-2008. Aceito para publicação em 13-01-2009.

${ }^{2}$ Eng. Agr. Mestre em Ciências Agrárias/Universidade Brasília, Campus Universitário Darcy Ribeiro, 70910-900 BrasíliaDF. bellon@cpac.embrapa.br

${ }^{3}$ Pesquisador da Embrapa Cerrados, BR 020, Km 18, Caixa Postal 08223, 73010-970 Planaltina-DF. ffaleiro@cpac.embrapa.br, junqueir@cpac.embrapa.br, fideles@cpac.embrapa.br

${ }^{4}$ Professor da Universidade de Brasília, UnB Campus Universitário Darcy Ribeiro, 70910-900 Brasília-DF. peixoto@unb.br ${ }^{5}$ Eng. Agr. Doutoranda em Fitotecnia/Universidade Brasília, Campus Universitário Darcy Ribeiro, 70910-900 Brasília-DF. keize@unb.br 


\section{INTRODUÇÃO}

O maracujá-doce (Passiflora alata Curtis), conhecido popularmente por maracujá-de- refresco, maracujá-de-comer, maracujá-alado ou maracujáguaçu, apresenta importância econômica como fruto para consumo in natura. Pode ser comercializado em embalagem especial ou vendido em unidades nos locais de melhor poder aquisitivo do Brasil, mas representa uma pequena parcela, quando comparado ao maracujazeiro-azedo (Junqueira et al., 2005). Apesar da grande importância econômica do maracujá-doce atual e potencial, ainda não há nenhuma cultivar comercial lançada no mercado com características definidas e garantia de origem.

Espécies silvestres de maracujazeiro apresentam ampla diversidade genética, disponibilizando grande potencial de genes e alelos de interesse para programas de melhoramento. Dentro da espécie $P$. alata, espera-se grande variabilidade de alelos, em função da sua ampla distribuição geográfica, com acessos encontrados em várias condições ambientais não só no País, como também no Peru e na Argentina (Braga et al., 2005).

Segundo Cunha (1998), estudos acurados e detalhados da variabilidade genética do maracujazeiro poderão indicar recursos genéticos valiosos, sejam novas espécies nos sistemas de produção como opções adicionais ao maracujazeirodoce, sejam genes de espécies silvestres úteis ao melhoramento das atuais espécies cultivadas, como P. edulis e P.alata. Para tais estudos, o uso de marcadores moleculares do DNA têm sido muito úteis por permitirem a obtenção de um número praticamente ilimitado de polimorfismo genético sem influência do ambiente bem como a detecção de tais polimorfismos em qualquer estádio do desenvolvimento da planta ou a partir de cultura de células ou tecidos (Faleiro, 2007)

Para complementar estudos de caracterização morfológica e agronômica, objetivou-se, neste trabalho, realizar o estudo da variabilidade de 17 acessos de $P$. alata mantidos no banco de germoplasma da Embrapa Cerrados, utilizando-se de marcadores moleculares RAPD ("Random Amplified Polymorphic DNA").

\section{MATERIAL E MÉTODOS}

Foram utilizados 17 acessos de maracujá-doce (Nove obtidos de populações cultivadas e oito de silvestres). Os nove acessos oriundos de populações cultivadas foram obtidos a partir de plantas com diferentes formatos de frutos, conforme proposta de Junqueira et al. (2005). Cada acesso foi obtido de sementes de frutos de uma planta-matriz selecionada dentro do Programa de Melhoramento Genético com base na produtividade e resistência a doenças. Cada acesso estudado neste trabalho foi representado pela planta-matriz. Um acesso de $P$. quadrangularis e um de $P$. edulis foram utilizados como "out group" (Tabela 1). Folhas de cada planta-matriz de cada acesso foram coletadas, e o DNA genômico extraído, utilizando o método do CTAB, com modificações (Faleiro et al., 2003). Amostras de DNA de cada material genético foram amplificadas para obtenção de marcadores RAPD.

As reações de amplificação foram feitas em um volume total de $13 \mu \mathrm{L}$, contendo Tris- $\mathrm{HCl} 10 \mathrm{mM}$ (pH 8,3), KCl 50 mM, MgCl2 3 mM, $100 \mu \mathrm{M}$ de cada um dos desoxiribonucleotídios (dATP, dTTP, dGTP e dCTP), 0,4 $\mu \mathrm{M}$ de um iniciador (Operon Technologies Inc., Alameda, CA, EUA), uma unidade da enzima Taq polimerase e, aproximadamente, 15 ng de DNA. Para a obtenção dos marcadores RAPD, foram testados, aproximadamente, 40 iniciadores decâmeros, sendo utilizados 11 iniciadores que geraram maior quantidade e qualidade das amplificações: OPD (04; 07; 08 e16), OPE (18 e 20), OPF (01 e 14 ), OPG (08), OPH (12 e 16). As amplificações foram efetuadas em termociclador programado para 40 ciclos, cada um constituído pela seguinte sequência: $15 \mathrm{~s} \mathrm{a} 94^{\circ} \mathrm{C}, 30 \mathrm{~s} \mathrm{a} 35^{\circ} \mathrm{C}$ e $90 \mathrm{~s} \mathrm{a}$ $72{ }^{\circ} \mathrm{C}$. Após os 40 ciclos, foi feita uma etapa de extensão final de seis min a $72{ }^{\circ} \mathrm{C}$, e, finalmente, a temperatura foi reduzida para $4{ }^{\circ} \mathrm{C}$. Após a amplificação, foram adicionados, a cada amostra, 3 $\mu \mathrm{l}$ de uma mistura de azul de bromofenol $(0,25 \%)$ e glicerol $(60 \%)$ em água. Essas amostras foram aplicadas em gel de agarose (1,2\%), corado com brometo de etídio, submerso em tampão TBE (TrisBorato $90 \mathrm{mM}$, EDTA $1 \mathrm{mM}$ ). A separação eletroforética foi de, aproximadamente, quatro horas, a 90 volts. Ao término da corrida, os géis foram fotografados sob luz ultravioleta.

Os marcadores RAPD gerados foram convertidos em matriz de dados binários, a partir da qual foram estimadas as distâncias genéticas entre os diferentes acessos, com base no complemento do coeficiente de similaridade de Nei \& Li (1979), utilizando-se do Programa Genes (Cruz, 2001). A matriz de distâncias genéticas foi utilizada para realizar análises de agrupamento, utilizando-se do método do UPGMA (Unweighted pair-group arithmetic average) como critério de agrupamento, e a dispersão gráfica, baseada em escalas multidimensionais usando o método das 
coordenadas principais, com auxílio do Programa SAS e Statistica (Statsoft Inc., 1999). O ajuste entre as matrizes de distância e o dendrograma foi estimado pelo coeficiente de correlação cofenética (r), conforme Sokal \& Rohlf (1962), por meio do programa computacional NTSYS pc 2.1 (Rohlf, 2000). A estabilidade dos agrupamentos foi computada por meio da análise de Bootstraping com 500 replicações por meio do programa Genes (Cruz, 2001).

\section{RESULTADOS E DISCUSSÃO}

Os 11 iniciadores decâmeros geraram um total de 140 marcadores RAPD, perfazendo uma média de 12,7 marcadores por iniciador. Do total de marcadores, considerando-se apenas os acessos de P. alata, observaram-se $87(62,12 \%)$ bandas polimórficas (Tabela 2). A alta média de marcadores por iniciador e a alta porcentagem de marcadores polimórficos dentro da espécie $P$. alata evidenciam a presença de alta variabilidade genética intraespecífica. A alta variabilidade genética interespecífica foi verificada ao analisarem-se as bandas polimórificas do acesso de $P$. edulis (outgroup) em relação aos acessos de P.alata. Faleiro et al. (2004), Pio Viana et al. (2003), Junqueira et al. (2006) e Bellon et al. (2007) já haviam relatado a alta variabilidade genética interespecífica no gênero Passiflora com base em marcadores RAPD. Segundo Lopes (1991), o gênero Passiflora é originário da América do Sul, com o Centro-Norte do Brasil, seu maior centro de dipersão geográfica, fato que pode explicar a grande variabilidade dos acessos estudados.

As distâncias genéticas entre os 17 acessos de maracujá-doce variaram entre 0,086 e 0,324 (dados não apresentados). Considerando apenas os acessos de população cultivada de $P$. alata, as distâncias genéticas variaram entre 0,086 a 0,171. As menores distâncias genéticas foram verificadas entre os acessos "Tipo A" e "Tipo D" e entre "Tipo I" e "Tipo J", sendo de 0,086 e 0,101, respectivamente. Já nos acessos silvestres, as distâncias variaram entre 0,096 e 0,324. A maior distância genética intraespecífica $(0,324)$ foi verificada entre os acessos silvestres "Brinco" e "Mato Grosso do Sul". Taxonomista da equipe envolvida no melhoramento genético do maracujazeiro suspeita que o acesso "Brinco" pertence à espécie Passiflora phenicia Lindd. e não à espécie Passiflora alata (Bernacci, L.C., comunicação pessoal).

A partir da análise de agrupamento realizada com base nas distâncias genéticas, subdividiram- se os 19 acessos em, pelo menos, sete grupos de similaridade genética, considerando o ponto de corte a uma distância genética de 0,15 (Figura 1). No entanto, quando se consideram apenas os 17 acessos de $P$. alata, cinco grupos podem ser definidos no dendrograma. O coeficiente de correlação cofenética do dendrograma $(r=0,97)$ revelou elevado ajuste entre a representação gráfica das distâncias genéticas e a matriz de distância genética original, o que assegura as inferências realizadas por meio da avaliação visual da Figura 1. Observa-se que os nove acessos de população cultivada selecionados no Distrito Federal ficaram no mesmo grupo de similaridade, o qual apresentou estabilidade de $75 \%$ como base em análises de bootstraping com 500 replicações. Os acessos do DF, GO e SC também formaram um grupo de similaridade, porém com uma estabilidade bem menor de $30 \%$.

No maior grupo de similaridade formado por 9 acessos de população cultivada de $P$. alata, todos procedentes do Distrito Federal, pode-se verificar maior similaridade entre os acessos P.alata "Tipo D" e P.alata "Tipo A" $(0,086)$ e entre $P$. alata "Tipo J" e $P$. alata "Tipo D" $(0,095)$. A similaridade desse grupo é explicada pela mesma origem genética dos acessos. Entretanto, observa-se uma variabilidade genética dentro do grupo, a qual pode ser explicada pela seleção prévia dos acessos com base no formato dos frutos (Tipos A, D, E, F, G, I e J) realizada por Junqueira et al. (2005).

Um grupamento com alta estabilidade $(68 \%)$ foi formado pelos acessos Silvestre 1 e Silvestre 2 provenientes do Distrito Federal. Também foram formados grupos envolvendo acessos silvestres, procedentes de regiões geográficas distintas. Os acessos "Mato Grosso do Sul" e "Brinco" foram os mais divergentes entre si $(0,324)$. $\mathrm{O}$ acesso que mais se distanciou geneticamente dos demais foi o P. edulis GA-2, utilizado como out group. A espécie $P$. quadrangularis, também utilizada como out group, apresentou-se mais próxima geneticamente dos acessos de $P$. alata, possivelmente devido à existência de compatibilidade genética com $P$. alata (Souza et al., 2006), o que permite a utilização de cruzamentos interespecíficos para ampliar ainda mais a base genética do maracujá-doce. 
TABELA 1- Espécies de maracujazeiro e respectivos acessos.

\begin{tabular}{|c|c|c|c|c|}
\hline $\mathrm{N}^{0}$ & Espécie & Acesso & Estado & Código \\
\hline 1 & $P a C$ & "Avó - Tipo I" & DF & CPAC MJ-02-01 \\
\hline 2 & $\mathrm{PaC}$ & "Avó - Tipo J" & DF & CPAC MJ -02-02 \\
\hline 3 & $\mathrm{PaC}$ & "Filha - Tipo A" & DF & CPAC MJ -02-03 \\
\hline 4 & $\mathrm{PaC}$ & "Filha - Tipo D" & DF & CPAC MJ -02-04 \\
\hline 5 & $\mathrm{PaC}$ & "Filha - Tipo E" & DF & CPAC MJ-02-05 \\
\hline 6 & $\mathrm{PaC}$ & "Filha - Tipo F" & DF & CPAC MJ -02-06 \\
\hline 7 & $\mathrm{PaC}$ & "Filha - Tipo G" & DF & CPAC MJ-02-07 \\
\hline 8 & $\mathrm{PaC}$ & "Filha - Tipo I" & DF & CPAC MJ $-02-08$ \\
\hline 9 & $\mathrm{PaC}$ & "Filha - Tipo J" & DF & CPAC MJ $-02-09$ \\
\hline 10 & $P a \mathrm{~S}$ & "Brinco" & $\mathrm{BA}$ & CPAC MJ -02-10 \\
\hline 11 & $\mathrm{PaS}$ & "4 nectários" & DF & CPAC MJ-02-12 \\
\hline 12 & $P a \mathrm{~S}$ & "Alto Paraíso" & GO & CPAC MJ -02-13 \\
\hline 13 & $\mathrm{PaS}$ & "Santa Catarina" & $\mathrm{SC}$ & CPAC MJ-02-14 \\
\hline 14 & $\mathrm{PaS}$ & "Mato Grosso do Sul" & MS & CPAC MJ-02-18 \\
\hline 15 & $P a \mathrm{~S}$ & "Silvestre 1" & DF & CPAC MJ-02-16 \\
\hline 16 & $P a \mathrm{~S}$ & "Silvestre 2" & DF & CPAC MJ-02-17 \\
\hline 17 & $\mathrm{PaS}$ & "Cerradão" & DF & CPAC MJ -02-15 \\
\hline 18 & $P q$ & "Comunidade Krahó" & TO & CPAC MJ-07-01 \\
\hline 19 & $\mathrm{Pe}$ & "GA-2" & DF & CPAC MJ-21-02 \\
\hline
\end{tabular}

$P a \mathrm{C}$ (Passiflora alata obtidos de populações cultivadas); $P a \mathrm{~S}$ (Passiflora alata obtidos de populações silvestres); $P q$ (Passiflora quadrangularis); Pe (Passiflora edulis). A terminologia "Tipo" refere-se ao formato de frutos, conforme proposta de Junqueira et al. (2005).
TABELA 2 - Iniciadores utilizados para a obtenção dos marcadores RAPD, com os respectivos números de bandas polimórficas e monomórficas

\begin{tabular}{|c|c|c|c|}
\hline Iniciado $\mathrm{r}$ & Sequência $5^{\prime} \quad 3^{\prime}$ & $\begin{array}{l}\mathrm{N}^{0} \text { de bandas } \\
\text { polimórficas }\end{array}$ & $\begin{array}{l}\mathrm{N}^{0} \text { de bandas } \\
\text { monomórficas }\end{array}$ \\
\hline OPD-04 & TCTGGTGAGG & 8 & 11 \\
\hline OPD-07 & TTGGCACGGG & 12 & 2 \\
\hline OPD-08 & GTGTGCCCCA & 2 & 5 \\
\hline OPD-16 & AGGGCGTAAG & 7 & 5 \\
\hline OPE-18 & GGACTGCAGA & 4 & 6 \\
\hline OPE-20 & AACGGTGACC & 4 & 5 \\
\hline OPF-01 & ACGGATCCTG & 6 & 5 \\
\hline OPF-14 & TGCTGCAGGT & 11 & 6 \\
\hline OPG-08 & TCACGTCCAC & 9 & 1 \\
\hline OPH-12 & ACGCGCATGT & 12 & 5 \\
\hline OPH 16 & TCTCAGCTGG & 12 & 2 \\
\hline \multicolumn{2}{|c|}{ TOTAL } & 87 & 53 \\
\hline
\end{tabular}

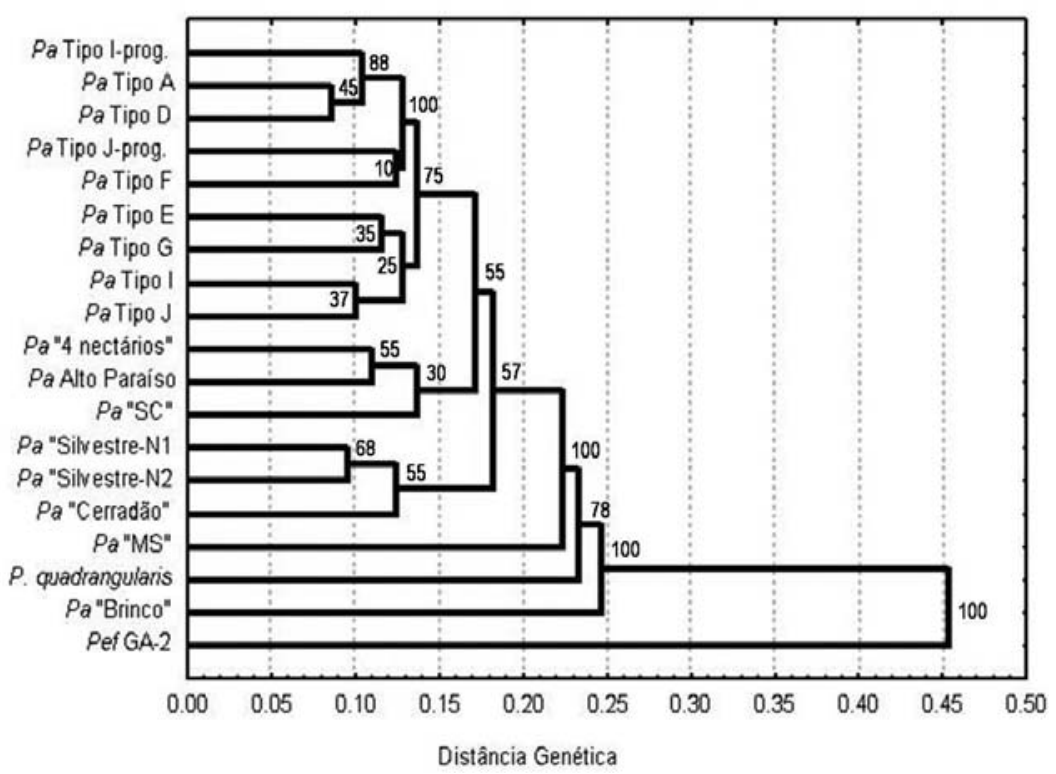

FIGURA 1- Análise de agrupamento de 19 acessos de maracujazeiro obtido a partir da matriz de distâncias genéticas calculadas com base no complemento do coeficiente de similaridade de Nei \& Li (1979), utilizando-se de 140 marcadores RAPD. Os números nas bifurcações correspondem à estabilidade dos agrupamentos calculados com base em análise de Bootstraping com 500 replicações. 


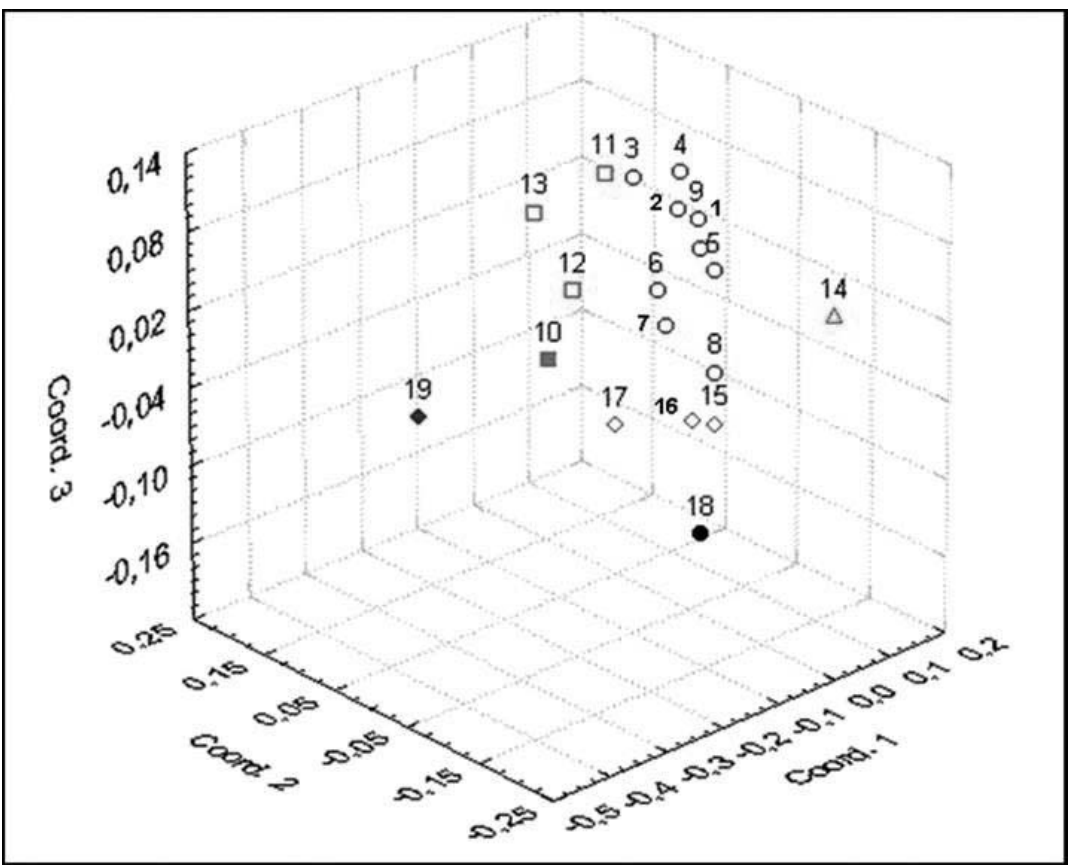

FIGURA 2- Dispersão gráfica de 19 acessos de maracujazeiro a partir da matriz de distâncias genéticas calculadas com base no complemento do coeficiente de similaridade de Nei \& Li (1979), utilizando-se de 140 marcadores RAPD. Os acessos com o mesmo símbolo formaram grupos de similaridade à distância relativa de 0,15 .

\section{CONCLUSÕES}

1-Verificou-se ampla variabilidade genética entre os acessos de população cultivada e silvestres de Passiflora alata.

2-Os acessos silvestres são os que mais podem contribuir para a ampliação da base genética dos materiais estudados.

3-A maior distância genética intraespecífica foi verificada entre os acessos silvestres "Brinco" e "Mato Grosso do Sul".

4-A similaridade genética verificada entre os acessos de Passiflora quadrangularis e P. alata explica a existência de compatibilidade genética entre essas duas espécies.

\section{REFERÊNCIAS}

BELLON, G.; FALEIRO, FALEIRO, F. G.; JUNQUEIRA, K. P.; JUNQUEIRA, N. T. V.; SANTOS, E. C.dos; BRAGA, M. F.; GUIMARÃES, C. T. Variabilidade genética de acessos silvestres e comerciais de Passiflora edulis Sims.,com base em marcadores RAPD. Revista Brasileira de Fruticultura, Jaboticabal, 2007, vol.29, n. 1,
BRAGA, M.F.; JUNQUEIRA, N.T.V.; FALEIRO, F.G.; BELLON, G.; JUNQUEIRA, K.P. Maracujá-doce: melhoramento genético e germoplasma. In: FALEIRO, F.G.; JUNQUEIRA, N.T.V.; BRAGA, M.F. (Ed.). Maracujá: germoplasma e melhoramento genético. Planaltina, DF: Embrapa Cerrados, 2005. p. 601-617.

CRUZ, C.D. Programa genes: aplicativo computacional em genética e estatística. Viçosa: UFV, 2001.648p.

CUNHA, M.A.P. da. Prioridades de pesquisa por subárea e objetivo. Cruz das Almas-BA: EMBRAPA/ CNPMF, 1998. p.11-14 (Documentos, 77).

FALEIRO, F. Marcadores moleculares aplicados a programas de conservação e uso de recursos genéticos. Planaltina-DF: Embrapa Cerrados, 2007. $102 \mathrm{p}$.

FALEIRO, F. G; JUNQUEIRA, N. T. V.; BELLON, G.; BORGES, T.A.;ANJOS,J.R.N.;PEIXOTO,J.R.;BRAGA, M. F.; SANTOS, D. G. Diversidade genética de espécies silvestres de maracujazeiro com resistência múltipla a doenças com base em marcadores RAPD. Fitopatologia Brasileira, Brasília, v. 29, p. S325, 2004. Suplemento. 
FALEIRO, F.G.; FALEIRO, A.S.G.; CORDEIRO, M.C.R.; KARIA, C.T. Metodologia para operacionalizar a extração de DNA de espécies nativas do cerrado. Planaltina: Embrapa Cerrados, 2003. 6 p. (Comunicado Técnico, 92)

JUNQUEIRA, K. P.; FALEIRO, F.G.; RAMOS, J.D.; BELLON, G.; JUNQUEIRA, N.T.V.; BRAGA, M.F. Confirmação de hibridações interespecíficas no gênero Passiflora por meio de marcadores RAPD. In: CONGRESSOBRASILEIRODEFRUTICULTURA, 19. 2006, Cabo Frio, RJ. Anais... p.384.

JUNQUEIRA, N.T.V.; PEIXOTO, J.R.;BRANCHER,A.; JUNQUEIRA, K.P.; FIALHO, J.de F. Melhoramento genético do maracujazeiro. In: MANICA, I. Maracujá-doce: tecnologia de produção e póscolheita, mercado. Porto Alegre: Editora Cinco Continentes, 2005. cap. 4, p. 39-46.

LOPES, S.C. Citogenética do maracujá, Passiflora spp. In: SÃO JOSÉ, A.R.; FERREIRA, F.R.; VAZ, R.L. (Eds.). A cultura do maracujá no Brasil. Jaboticabal: FUNEP, 1991.p. 201-209.

NEI, M.; LI, W.H. Mathematical model for studying genetic variation in terms of restriction endonucleases. Proceedings of the National Academy of Science, Washington, v.76, p. 5269-5273, 1979.
PIO VIANA, A.; PEREIRA, T. N. S.; PEREIRA, M. G.; SOUZA, M. M.; MALDONADO, F.; AMARAL JÚNIOR, A. T. Diversidade entre genótipos de maracujazeiro amarelo (Passiflora edulis f. flavicarpa) e entre espécies de passifloras determinada por marcadores RAPD. Revista Brasileira de Fruticultura, Jaboticabal, v. 25, n. 3, p. 489-493, 2003.

ROHLF, F. J. NTSYS-pc: numerical taxonomy and multivariate analysis system, version 2.1. New York: Exeter Software, 2000. 98p.

SOKAL, R.R.; ROHLF, F.J. The comparison of dendrograms by objective methods. Taxon, Utrecht, v.11, p.30-40, 1962.

SOUZA, L.S.; JUNQUEIRA, N.T.V.; LIMA, C.A.; BERNACCI, L.C.; VAZ, C.F.; SILVA, D.G.P.; BRAGA, M.F.; FALEIRO, F.G.; SANTOS, E.C. Índice de cruzabilidade entre espécies de passifloras nas condições do Distrito Federal. In: CONGRESSO BRASILEIRO DE FRUTICULTURA, FRUTAS DO BRASIL: SAÚDE PARA O MUNDO, 2006. Cabo Frio. Palestras e Resumos... 2006. p.244.

STATSOFT. Statistica for Windows [Computer program manual] Tulsa, OK, 1999. 